\title{
Klebsiella pneumoniae isolated from bovine mastitis is cytopathogenic for bovine mammary epithelial cells
}

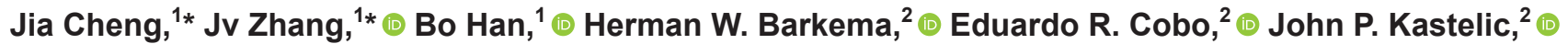 \\ Man Zhou, ${ }^{1}$ Yuxiang Shi, ${ }^{3}$ Jianfang Wang, ${ }^{4}$ Rui Yang, ${ }^{5}$ and Jian Gao ${ }^{1} \dagger \odot$ \\ ${ }^{1}$ Department of Clinical Veterinary Medicine, College of Veterinary Medicine, China Agricultural University, Beijing 100193, P.R. China \\ ${ }^{2}$ Department of Production Animal Health, Faculty of Veterinary Medicine, University of Calgary, Canada, T2N 4N1 \\ ${ }^{3}$ College of Life Sciences and Food Engineering, Hebei University of Engineering, 056038, P.R. China \\ ${ }^{4}$ Beijing Key Laboratory of Traditional Chinese Veterinary Medicine, Beijing University of Agriculture, Beijing 102206, P.R. China \\ ${ }^{5}$ Beijing Key Laboratory for Agricultural Application and New Technique, Beijing University of Agriculture, Beijing 102206, P.R. China
}

\begin{abstract}
Klebsiella pneumoniae, a common cause of clinical mastitis (CM) in dairy cows, can cause severe clinical symptoms. However, its pathogenicity in the bovine mammary gland is not well understood. Our objectives were to establish an in vitro infection model of K. pneumoniae on bovine mammary epithelial cells (bMEC) to assess (1) cytopathogenicity (adhesive and invasive ability, damage and apoptosis, pro-inflammatory effects) of K. pneumoniae on bMEC and (2) the role of hypermucoviscous (HMV) phenotype on cytopathogenicity. Two K. pneumoniae isolates from CM cows, $1 \mathrm{HMV}$ and 1 non-HMV, were used to infect bMEC. Adhesion and invasion ability, release of lactate dehydrogenase (LDH), ultrastructural morphology, apoptosis, transcriptional expression of pro-inflammatory genes and production of pro-inflammatory cytokines were characterized at various intervals. Both $K$. pneumoniae isolates rapidly adhered to and invaded bMEC within $1 \mathrm{~h}$ post infection (pi), causing ultrastructural damage (swelling of mitochondria and vesicle formation on cell surface) after $3 \mathrm{~h}$ pi and apoptotic death after $9 \mathrm{~h}$ pi. In addition, $K$. pneumoniae promoted transcriptional expression of pro-inflammatory genes IL-6, IL-8, IL-1 $\beta$, and tumor necrosis factor (TNF)- $\alpha$ and production of IL-8, IL-1 $\beta$, and TNF- $\alpha$ cytokines. Compared with non-HMV $K$. pneumoniae, the HMV isolate had lower adhesive and invasive abilities but caused more serious cellular damage. In conclusion, K. pneumoniae was cytopathogenic on bMEC and induced a pro-inflammatory response; however, the HMV phenotype did not have a key role in pathogenicity. Therefore, more attention should be
\end{abstract}

Received August 15, 2019.

Accepted December 3, 2019.

*These authors contributed equally to this work.

†Corresponding author: gaojian2016@cau.edu.cn paid to milk loss, and targeted prevention and treatment strategies should be implemented in Klebsiella mastitis episodes.

Key words: bovine mastitis, Klebsiella pneumoniae, bovine mammary epithelial cells (bMEC), apoptosis, inflammation

\section{INTRODUCTION}

Bovine clinical mastitis $(\mathbf{C M})$ is a common and costly disease in the dairy industry worldwide, which can be caused by many pathogens, with Klebsiella pneumoniae considered a major pathogen (Roberson et al., 2004; Olde Riekerink et al., 2008; Oliveira et al., 2013). Klebsiella CM is often severe and does not respond well to antimicrobial treatment, resulting in prolonged duration of intramammary infection and substantial loss of milk yield (Schukken et al., 2012). Virulence factors may be a crucial reason for severity of intramammary infection with $K$. pneumoniae. Capsular serotypes, iron-scavenging systems, and fimbriae have widely been reported to be involved in virulence of K. pneumoniae from human origin (Holt et al., 2015). Recently, a new hypervirulent $K$. pneumoniae with a hypermucoviscous (HMV) phenotype has emerged and attracted worldwide attention (Shon et al., 2013). Klebsiella pneumoniae, when hypermucoid, can cause invasive disease in humans and in several animal species (Twenhafel et al., 2008; Jang et al., 2010; Holt et al., 2015; Davies et al., 2016). However, whether HMV K. pneumoniae can cause CM with severe clinical symptoms in cattle has apparently not been reported.

Bovine mammary epithelial cells (bMEC) are the udder's functional, milk-producing cells. After pathogenic infection, bMEC can be damaged and undergo apoptosis, decreasing milk production. The ability of an intracellular pathogen to adhere to and invade bMEC could confer protection from the immune system and from antibacterial agents, predisposing to development 
of a chronic infection (Almeida et al., 2011). In addition, because bMEC are front-line cells, they may act as sentinels by producing mediators of inflammation and local defenses against pathogens (Gilbert et al., 2013).

Distribution of virulence factors implicated $r m p A$, $k f u$, uge, magA, aerobactin, and $\mathrm{K} 1$ and $\mathrm{K} 2$ in pathogenicity of $K$. pneumoniae isolated from bovine mastitis (Osman et al., 2014). Distribution of potential virulence factors in $K$. pneumoniae from cows with $\mathrm{CM}$ on Chinese dairy farms has also been determined (Gao et al., 2019). Therefore, it is very important to establish a bacterial infection model with bMEC to facilitate studying virulence of $K$. pneumoniae. Objectives of the present study were (1) to determine cytopathogenicity (adhesive and invasive ability, damage and apoptosis, and pro-inflammatory effect) of $K$. pneumoniae on bMEC, and (2) to explore whether HMV phenotype increases cytopathogenicity of $K$. pneumoniae on bMEC. Results of the present study would be useful to determine whether more effort should be given to minimizing milk loss during and after episodes of mastitis caused by $K$. pneumoniae, especially concerning HMV isolates.

\section{MATERIALS AND METHODS}

\section{Statement of Ethics}

Approval was granted by the Ethical Committee of the College of Veterinary Medicine, China Agricultural University (CAU), Beijing, and the study was conducted according to the standard ethical guidelines of CAU. Milk samples from cows with CM were collected according to National Mastitis Council (NMC, 2017) standard procedures, with appropriate consultation with farm owners and management.

\section{Klebsiella pneumoniae Isolates}

Cases of CM were detected at milking and confirmed by herd veterinarians, who collected milk samples aseptically from quarters with visible signs of CM (abnormal milk, swelling) before antibiotic treatment, following standardized protocols (NMC, 2017). Milk samples were initially stored in a freezer (approximately $-20^{\circ} \mathrm{C}$ ) and then placed on ice and sent to the Mastitis Diagnostic Laboratory, China Agriculture University (MDL-CAU; Beijing, P.R. China) for culture. A total of $124 \mathrm{CM}$ isolates obtained from March 2014 to May 2017 were preliminarily identified as K. pneumoniae, as previously described (Gao et al., 2017), including colony characteristics on MacConkey agar, Gram staining, motility, indole, ornithine reactions, oxidase, and growth on triple-sugar iron slants. Presumptive K. pneumoniae isolates were further confirmed using partial $16 \mathrm{~S} \mathrm{rDNA}$ sequencing (Barry et al., 1990). Each K. pneumoniae isolate was isolated from 1 milk sample collected from a single CM case, with 124 isolates from $124 \mathrm{CM}$ quarter milk samples. Capsule serotypes (K1, K2, K5, K54, and K57) and existence of several virulence genes in $K$. pneumoniae isolates were confirmed using PCR (Gao et al., 2019). Isolates were classified as HMV or non-HMV phenotype via string test: a bacterial loop was used to stretch a "string" of mucus from the bacterial colony, with formation of a viscous string $>5 \mathrm{~mm}$ defined as a positive test (Fang et al., 2004). Finally, 2 K. pneumoniae isolates (HB-AF5 and HLJ-D2) were used in the present study. Both HB-AF5 and HLJ-D2 belonged to K57 capsule serotype and had entB, ybtS, iutA, and $m r k D$ genes, although the HLJ-D2 isolate had an extra kfu gene (Gao et al., 2019). HLJ-D2 was an HMV isolate, whereas HB-AF5 was a non-HMV isolate.

\section{Bovine Mammary Epithelial Cells}

We grew bMEC MAC-T (Shanghai Jingma Biological Technology Co. Ltd., Shanghai, China) to confluence in culture dishes in Dulbecco's modified Eagle's medium (DMEM) with high glucose (HyClone, Logan, UT) supplemented with $10 \%$ heat-inactivated fetal bovine serum (Gibco, Grand Island, NY), 100 IU/mL penicillin (HyClone), and $100 \mu \mathrm{g} / \mathrm{mL}$ streptomycin (HyClone) at $37^{\circ} \mathrm{C}$ incubator with $5 \% \mathrm{CO}_{2}$ on cell culture plates (Corning Inc., Corning, NY). At 70 to $80 \%$ confluence, cells were detached and plated in 6-well or 96-well plates. Subsequently, cells were challenged with HMV or non-HMV K. pneumoniae when they reached 80 to $90 \%$ confluence, whereas control cells were cultured only with culture medium. For detection of adhesion and invasion, ultrastructural morphology, apoptosis, and pro-inflammatory gene expression of bMEC, cells were cultured in 6 -well plates. Three wells were used to challenge with HMV or non-HMV K. pneumoniae in 1 specific time point, whereas the other 3 wells were used as control. For lactate dehydrogenase (LDH) detection, cells were cultured in 96-well plates. Five wells of cells were used to challenge with HMV or non-HMV $K$. pneumoniae in 1 specific time point, whereas 5 wells of cells were used as control. All challenges were repeated 3 times.

\section{Adhesion and Invasion}

First, quantities of bMEC per well were calculated using Trypan Blue staining, whereas counts (cfu) were performed using a WGZ-2XJ bacterial turbidimeter 
(Shanghai Xinrui Instrument Co. Ltd., Shanghai, China). Subsequently, K. pneumoniae were diluted using DMEM (Hyclone) for adhesion and invasion detection according to multiplicity of infection (MOI) of 50:1 ratio of $K$. pneumoniae to bMEC. In 6-well plates bMEC were incubated with $K$. pneumoniae $(2 \mathrm{~mL} /$ well) at $0.5,1,1.5,2$, or $3 \mathrm{~h}$ at $37^{\circ} \mathrm{C}$ with $5 \% \mathrm{CO}_{2}$. Additionally, in our preliminary experiments, we tested kanamycin (Sigma-Aldrich; St. Louis, MO) at 25, 50, 100 , and $150 \mu \mathrm{g} / \mathrm{mL}$ for 1,2 , and $3 \mathrm{~h}$; we found that 50 $\mu \mathrm{g} / \mathrm{mL}$ kanamycin killed K. pneumoniae $\left(1 \times 10^{7} \mathrm{cfu} /\right.$ $\mathrm{mL}$ ) within $2 \mathrm{~h}$. Therefore, $50 \mu \mathrm{g} / \mathrm{mL}$ kanamycin for $2 \mathrm{~h}$ was used for the invasion assay of $K$. pneumoniae.

Adhesion of K. pneumoniae to bMEC was assessed as previously described (Pereyra et al., 2016), with slight modifications; bMEC were cultured in 6-well plates (Corning Inc.). After incubation, samples were washed 3 times using sterile PBS and collected with $0.5 \mathrm{~mL}$ of PBS (Solarbio, Beijing, China; pH 7.2; Chen et al., 2017). Cell suspension was 10-fold serially diluted and cultured on trypticase soy agar (TSA) plate $\left(37^{\circ} \mathrm{C}, 20\right.$ h) for counting colony-forming units.

Invasion of bMEC was determined as described previously (Chen et al., 2017), with minor modifications. We inoculated bMEC with bacteria at an MOI ratio of 50:1 for up to $3 \mathrm{~h}$, washed them with PBS, and treated them with kanamycin $(50 \mu \mathrm{g} / \mathrm{mL} ; 2$ h) to kill extracellular $K$. pneumoniae. Cell lysates were then obtained with $1 \mathrm{~mL}$ of $5 \%$ TritonX-100 (Solarbio). In the control group, cells were also lysed with $1 \mathrm{~mL}$ of TritonX-100, and cell lysates were diluted 10-fold, cultured on TSA plate, and incubated at $37^{\circ} \mathrm{C}$ for $24 \mathrm{~h}$ to count colonyforming unitsCFU.

\section{Cytotoxic LDH Release Assay}

Cytotoxic effects of $K$. pneumoniae on bMEC were assessed using an LDH assay kit (Beyotime Institute of Biotechnology, Beijing, China). Cells cultured at $37^{\circ} \mathrm{C}$ with $5 \% \mathrm{CO}_{2}$ in 96-well plates (Corning Inc.) were challenged with $K$. pneumoniae at MOI ratio of K. pneumoniae to cells of $5: 1$ for $3,6,9$, and $12 \mathrm{~h}$. Noninfected cells were similarly incubated as control. After incubation, $200 \mu \mathrm{L}$ of supernatants from each well was collected and transferred to centrifuge tubes and spun $(8,000 \times g, 5 \mathrm{~min})$. Then, $120 \mu \mathrm{L}$ of supernatant was sequentially transferred to a new 96 -well polystyrene plate, with $60 \mu \mathrm{L}$ of reaction mixture added to each well, followed by incubation on a rotary shaker (150 $\mathrm{rpm})$ at room temperature in the dark for $30 \mathrm{~min}$. Absorbance was read at $490 \mathrm{~nm}$ (680 Multipurpose Microplate Reader, Biorad, Hercules, CA).

\section{Ultrastructural Morphology}

Ultrastructural analysis of bMEC inoculated with $K$. pneumoniae was determined using scanning electron and transmission electron microscopy. After incubation with K. pneumoniae, bMEC were washed with PBS and fixed with $2.5 \%$ glutaraldehyde (Solarbio; $4^{\circ} \mathrm{C}, 90 \mathrm{~min}$ ), then washed with PBS, and fixed cells were harvested with a rubber scraper (Thermo Fisher Scientific, Nepean, ON, Canada). Cells were then dehydrated in graded ethanol (from 30 to 100\%), dried using the criticalpoint drying method, and gold-coated with E-1010 Ion Sputter Coater (Hitachi, Tokyo, Japan) as described by Shahid et al. (2017). Finally, the changes in bMEC were observed via scanning electron microscopy (Tescan 5136, Brno, Czech Republic).

For transmission electron microscopy, bMEC were cultured and challenged as described above. After washing with PBS, cells were fixed with $2 \%$ glutaraldehyde- $1 \%$ paraformaldehyde solution (Sinopharm Chemical Reagent Co. Ltd., Shanghai, China; pH 7.2) for 45 min at room temperature. After washing with PBS, the fixed cells were harvested with a rubber scraper (Thermo Fisher Scientific). Then cells were dehydrated using graded ethanol and acetone (3 changes, 10 min each) and sequentially embedded in epoxy resin acetone mixtures $(2: 1)$ for $2 \mathrm{~h}$ and in pure resin overnight at $37^{\circ} \mathrm{C}$. After resin had polymerized, ultra-thin sections were cut (Leica EM, Wetzlar, Germany), stained with $1 \%$ uranyl acetate followed by lead citrate, and viewed with a transmission electron microscope (Hitachi H-7650) at $80 \mathrm{kV}$. Imaging was performed using a $4 \mathrm{k}$ CCD camera (Gatan Inc., Pleasanton, CA) and iTEM software. Damaged mitochondria, desquamation, microvilli breakage, and disruption of cellular cytomembrane were checked to evaluate the damage of bMEC.

\section{Apoptosis}

The bMEC inoculated with $K$. pneumoniae were stained with FITC annexin V/propidium iodide (PI), and cell apoptosis was determined using an annexin V-FITC/PI apoptosis detection kit (Beyotime) according to the manufacturer's instructions. Briefly, bMEC were inoculated with $K$. pneumoniae (MOI 5:1) for up to $12 \mathrm{~h}$ at $37^{\circ} \mathrm{C}$ with $5 \% \mathrm{CO}_{2}$. Cells not inoculated with $K$. pneumoniae were used as a control group. After incubation, cells were washed 3 times, collected with cold $\left(4^{\circ} \mathrm{C}\right) \mathrm{PBS}$, and centrifuged $(1,000 \times g, 5 \mathrm{~min}$ at $4^{\circ} \mathrm{C}$ ). Subsequently, cells were resuspended with $100 \mu \mathrm{L}$ of binding buffer and stained with $5 \mu \mathrm{L}$ of fluorescein isothiocyanate (FITC) annexin V conjugate and $5 \mu \mathrm{L}$ 
of PI (room temperature, $15 \mathrm{~min}$ ). Binding buffer (400 $\mu \mathrm{L}$ ) was added to samples, and apoptosis was analyzed within $1 \mathrm{~h}$ using a BD FacsCalibur flow cytometer (Becton Dickinson, Bergen City, NJ).

\section{Pro-Inflammatory Genes of bMEC}

Samples were collected for RNA extraction from inoculated and control (non-infected) cells at 3, 6, 9 , and $12 \mathrm{~h}$ post infection (pi). Briefly, bMEC were washed with PBS and harvested with $1 \mathrm{~mL}$ of Trizol to extract total RNA, according to manufacturer's protocol (TransGen Biotech Co. Ltd., Beijing, China). Total RNA yield and purity were determined by absorbance at 260 and $280 \mathrm{~nm}$ using a NanoDrop-2000 spectrophotometer (Thermo Fisher Scientific). Reverse transcription was performed with a transcript firststrand cDNA synthesis kit (TransGen Biotech Co. Ltd.), whereas quantitative real-time PCR analysis was performed with a qPCR detection kit (SYBR Green) on an ABI StepOnePlus Real-Time PCR System with Tower (ABI, Redlands, CA). Primers for the housekeeping gene (GAPDH; Zbinden et al., 2015) and genes encoding tumor necrosis factor- $\alpha$ (TNF- $\alpha)$, IL-1 $\beta$, IL6 , and IL-8 were obtained from published sequences (Beijing Sunbiotech Co. Ltd., Beijing, China; Zbinden et al., 2014, 2015) and presented in Table 1. The cycle threshold (Ct) values (Rotor-Gene software, Version 1.7, Corbett Life Science, Sydney, Australia) and $2^{-\Delta \Delta c t}$ values were chosen to reflect relative mRNA expression, using GAPDH and ACTB as reference genes (Table 1).

\section{Production of Pro-Inflammatory Cytokines}

Concentrations of pro-inflammatory cytokines TNF- $\alpha$, IL-1 $\beta$, IL-6, and IL-8 in cell supernatant were measured using an ELISA kit with a detection range of
0.1 to $20.0 \mathrm{ng} / \mathrm{mL}$ (Wuhan Huamei Bioengineering Co. Ltd., Wuhan, China). All procedures were performed following manufacturer's instructions. Data acquisition was performed using a Thermo K3 microplate reader (Thermo Fisher Scientific). Cytokines were quantitatively measured in culture supernatants from bMEC inoculated with HMV and non-HMV K. pneumoniae at MOI of 5 during 3, 6, 9, and $12 \mathrm{~h}$.

\section{Statistical Analyses}

Analyses were performed using one-way ANOVA, followed by the Duncan and LSD multiple tests, using SPSS 20.0 (SPSS Inc., Chicago, IL). All values were expressed as mean \pm standard error of the mean. All measurements were replicated 3 times. Differences were considered significant if $P<0.05$.

\section{RESULTS}

\section{Adhesion and Invasion}

Both HMV and non-HMV K. pneumoniae quickly and similarly adhered to bMEC (from 0.5 to $1.5 \mathrm{~h}$ pi; Figure 1A). However, at $2 \mathrm{~h} \mathrm{pi,} \mathrm{non-HMV} \mathrm{K.} \mathrm{pneumoniae}$ adhered at higher quantities compared with the HMV isolate $(P<0.01)$. Both $K$. pneumoniae isolates rapidly invaded bMEC (1 h pi), followed by higher invasiveness for non-HMV K. pneumoniae (until $3 \mathrm{~h}$ pi; Figure 1B).

\section{Ultrastructural Damage of bMEC}

As assessed by scanning electron microscopy (Figure 2), both HMV and non-HMV K. pneumoniae induced cell shrinkage and damage, producing holes on bMEC surfaces $(3 \mathrm{~h} \mathrm{pi})$ and vacuole formation with cell membrane breakage ( $6 \mathrm{~h} \mathrm{pi}$ ). At $9 \mathrm{~h} \mathrm{pi}$, both $K$. pneumoniae

Table 1. List of primers for real-time $\mathrm{PCR}^{1}$

\begin{tabular}{|c|c|c|c|c|}
\hline Gene & Primer & Sequence $5^{\prime}-3^{\prime}$ & $\begin{array}{l}\text { Size } \\
\text { (bp) }\end{array}$ & $\begin{array}{c}\text { Annealing } \\
\text { temperature }\left({ }^{\circ} \mathrm{C}\right)\end{array}$ \\
\hline$G A P D H$ & $\begin{array}{l}\text { Forward } \\
\text { Reverse }\end{array}$ & $\begin{array}{l}\text { GTCTTCACTACCATGGAGAAGG } \\
\text { TCATGGATGACCTTGGCCAG }\end{array}$ & 197 & 60 \\
\hline IL 6 & $\begin{array}{l}\text { Forward } \\
\text { Reverse }\end{array}$ & $\begin{array}{l}\text { CTTCACAAGCGCCTTCACTC } \\
\text { GTCAGAAGTAGTCTGCCTGC }\end{array}$ & 132 & 60 \\
\hline$I L 1 B$ & $\begin{array}{l}\text { Forward } \\
\text { Reverse }\end{array}$ & $\begin{array}{l}\text { ATGACTTCCAAGCTGGCTGTTG } \\
\text { TTGATAAATTTGGGGTGGAAAG }\end{array}$ & 114 & 60 \\
\hline
\end{tabular}

${ }^{1} T N F A=$ tumor necrosis factor- $\alpha$. Cycle threshold $(\mathrm{Ct})$ values were determined and relative mRNA expression was calculated using the comparative Ct method, as described by Zbinden et al. (2015). 

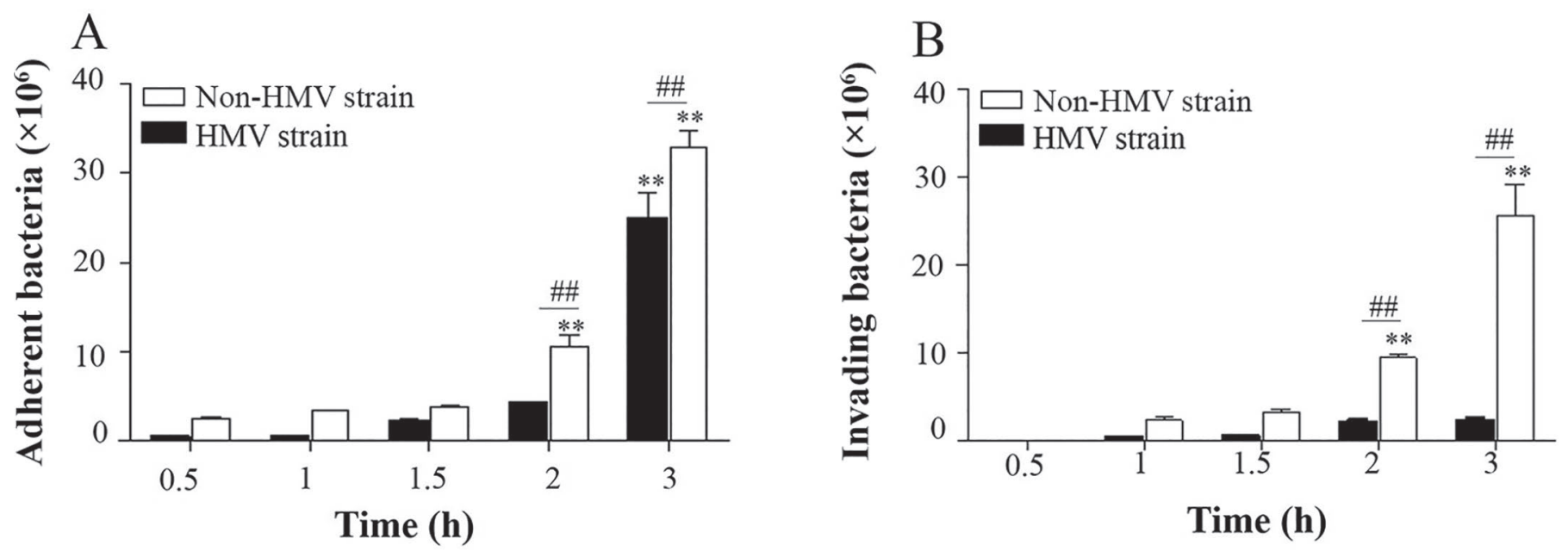

Figure 1. Adhesion and invasion of hypermucoviscous (HMV) and non-HMV Klebsiella pneumoniae in bovine mammary epithelial cells. (A) Adhesion and (B) invasion of $K$. pneumoniae isolates (up to $3 \mathrm{~h}$ post infection). Same isolate but compared with previous time point: ${ }^{*}=$ $P<0.05 ;{ }^{* *}=P<0.01$. HMV isolate compared with non-HMV isolate at the same time point: \#\# $=P<0.01$. Data are presented as mean $\pm \mathrm{SEM}$ of 3 independent experiments.

isolates caused desquamation and microvilli breakage to total disruption of bMEC cytomembranes (Figure $2)$. These morphological changes were more evident on bMEC infected with the HMV isolate (Figure 2).

Based on transmission electron microscopy, both isolates induced slight swelling, chromatin margination, and cristae degeneration of mitochondria $(3$ and $6 \mathrm{~h}$ pi), followed (9 h pi) by cytomembrane disruption and severe cytoplasm vacuolation with swollen endoplasmic reticulum (Figure 3). The non-HMV isolate induced irregularities of nuclear membranes, whereas the HMV isolate induced severe mitochondria swelling and disruption and cribriform appearance in cytoplasm. The HMV isolate was highly invasive at $12 \mathrm{~h}$, with cell rupture and loss of organelles (Figure 3). Uninfected bMEC lacked morphological changes, with a rich microvillus on the surface and normal structures with intact cytoplasm and organelles (Figure 3).

\section{Cytotoxicity and Apoptosis}

At 3 and $6 \mathrm{~h}$ pi, we found no difference between $\mathrm{HMV}$ and non-HMV isolates for $\mathrm{LDH}$ release (Figure 4A). Both isolates induced cytotoxic effects on bMEC at 9 and $12 \mathrm{~h}$ pi $(P<0.01)$ as determined by LDH release (Figure $4 \mathrm{~A}$ ).

Similarly, compared with a negative control group, the proportion of apoptotic bMEC in the HMV or nonHMV groups did not notably increase at 3 and $6 \mathrm{~h}$ pi, whereas this was different in bMEC incubated with HMV or non-HMV K. pneumoniae at 9 and $12 \mathrm{~h}$ pi $(P<0.01)$, as determined by annexin V-FITC and PI (Figures 4B and C).

\section{Gene Expression and Production of Pro-Inflammatory Cytokines}

For transcriptional mRNA of gene coding, both isolates induced release of pro-inflammatory cytokines, including TNF- $\alpha$, IL-1 $\beta$, IL- 6 , and IL- 8 in bMEC at 6 and $9 \mathrm{~h}$ pi $(P<0.01 ;$ Figure 5$)$. In addition, the HMV isolate provoked a more pronounced pro-inflammatory response at 6 and $9 \mathrm{~h}$ pi $(P<0.01$; Figure 5$)$.

Regarding cytokine production, secreted IL-6, IL-8, IL-1 $\beta$, and TNF- $\alpha$ were higher in infected bMEC compared with the non-infected group (Figure 6). Compared with controls (non-infected group), the HMV isolate induced higher $(P<0.01)$ production of IL-6 at $12 \mathrm{~h} \mathrm{pi}$; IL- 8 at 3,6 , and $9 \mathrm{~h}$ pi; and TNF- $\alpha$ at 6,9 , and $12 \mathrm{~h}$ pi (Figure 6). Furthermore, compared with controls, the non-HMV isolate induced higher $(P<0.01)$ production of IL- 8 at 3,6 , and $9 \mathrm{~h} \mathrm{pi}$; and IL- $1 \beta$ at 9 and $12 \mathrm{~h}$ (Figure 6). Furthermore, IL- 8 and TNF- $\alpha$ production were higher in bMEC exposed to the HMV than to the non-HMV isolate, which was different at $3(P<0.01)$ and $6 \mathrm{~h}$ pi $(P<0.05)$ for IL-8 (Figure $6 \mathrm{~B})$ and at $6 \mathrm{~h}$ pi for TNF- $\alpha(P<0.01$; Figure $6 \mathrm{D})$. In contrast, IL-1 $\beta$ production was higher in bMEC induced by the nonHMV isolate compared with the HMV isolate at 6 and $9 \mathrm{~h}$ pi (Figure 6C; $P<0.01$ ).

\section{DISCUSSION}

During episodes of bovine CM, bMEC have crucial roles in conferring protection against microbial pathogens by undergoing cell damage and apoptosis and releasing inflammatory cytokines (Chen et al., 2017; Sha- 

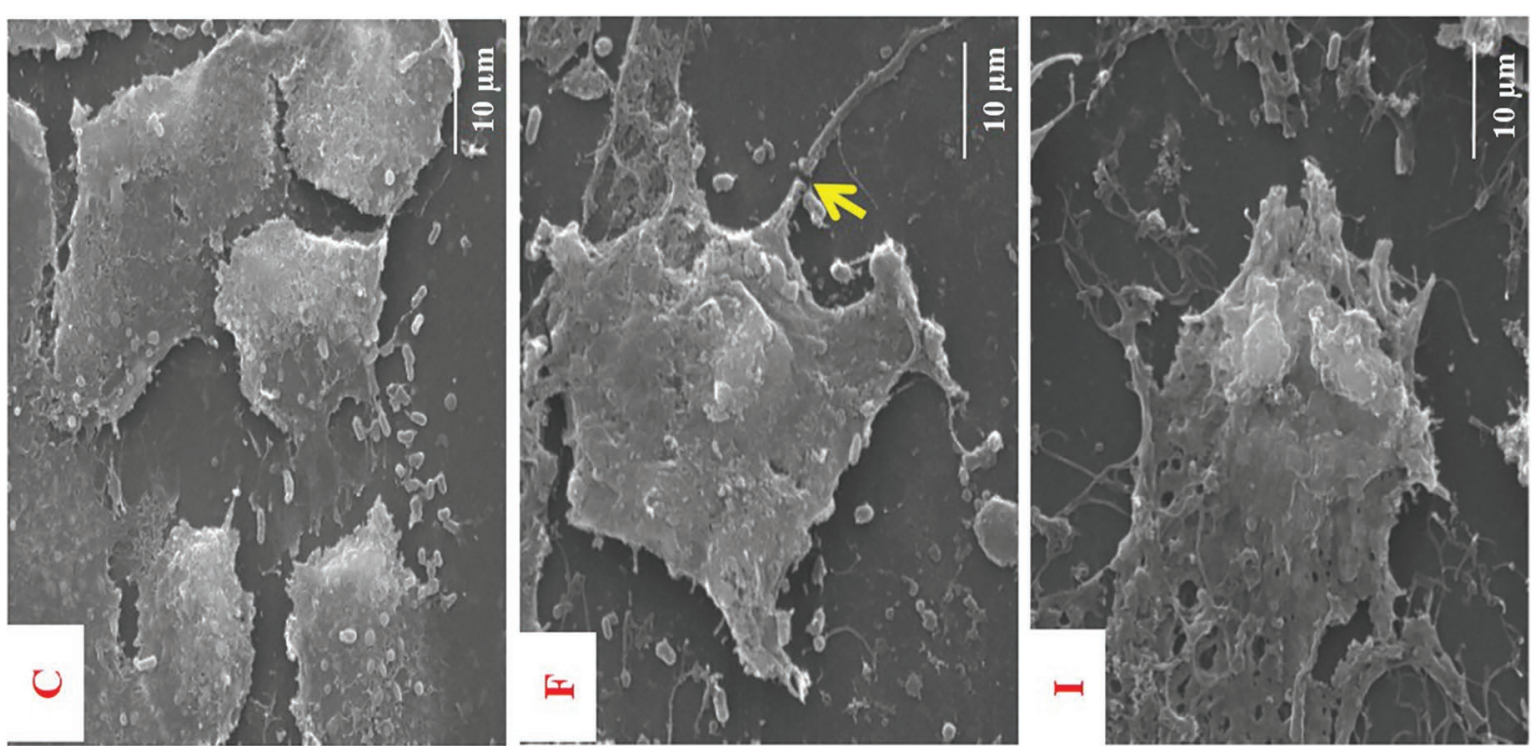

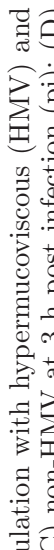

.

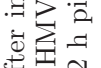

跑

田
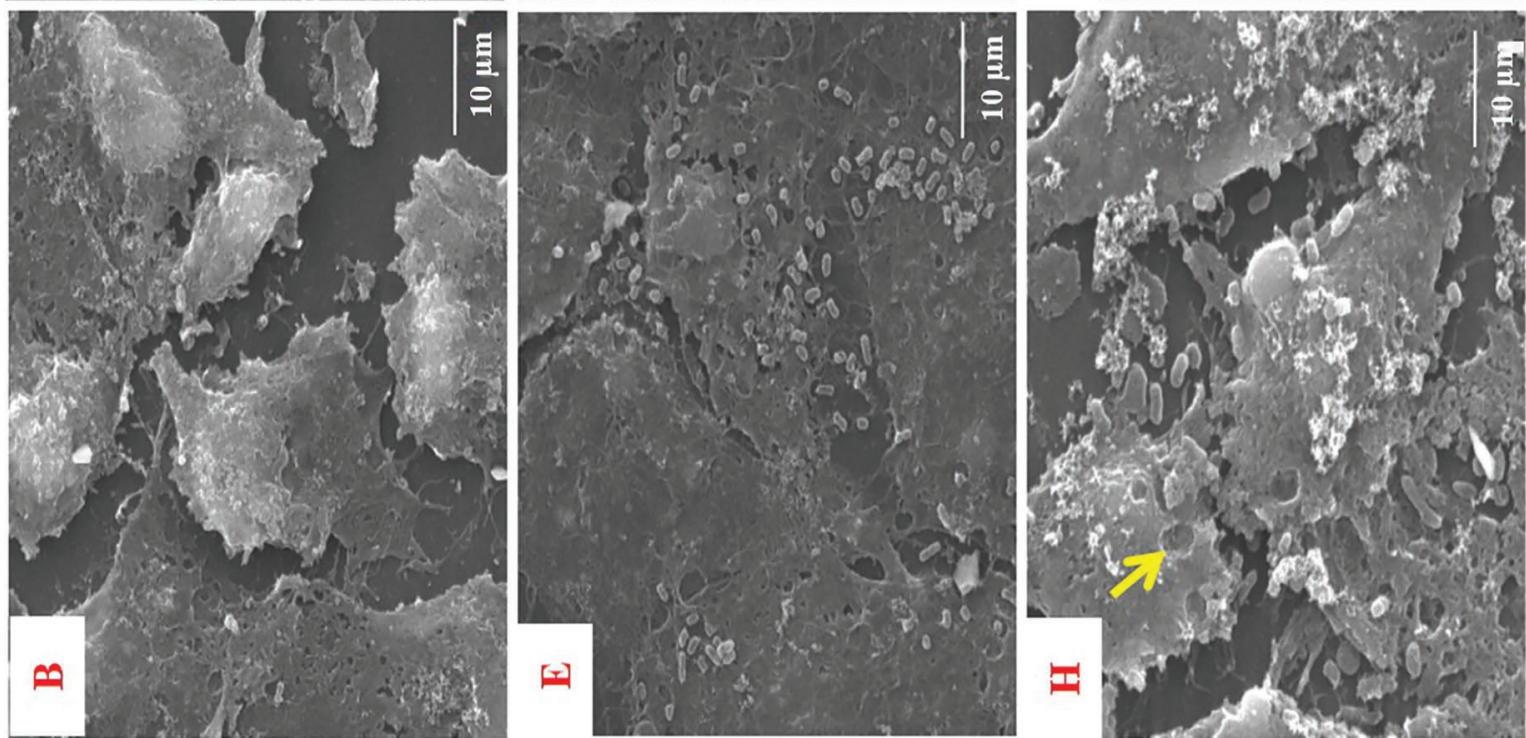

$\oplus$
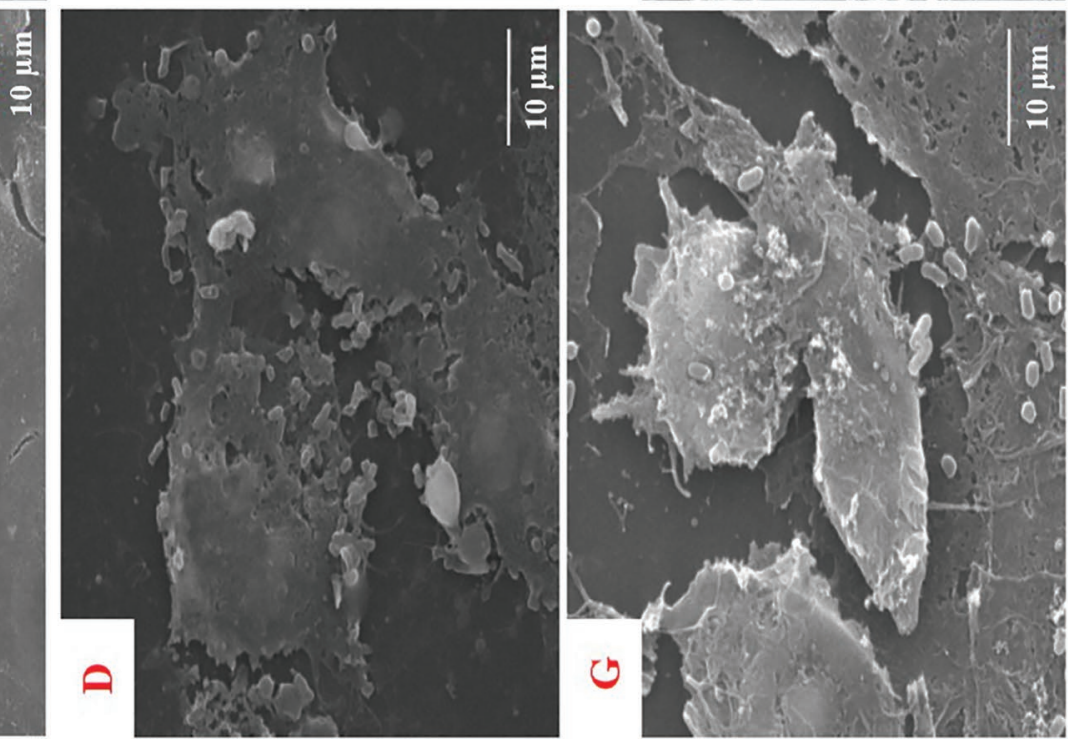

远

?

$\vec{\sigma} \cdot \overrightarrow{0}$

$\bar{g}$

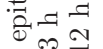

远语

密

包

要

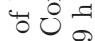

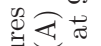

苞

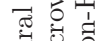

를

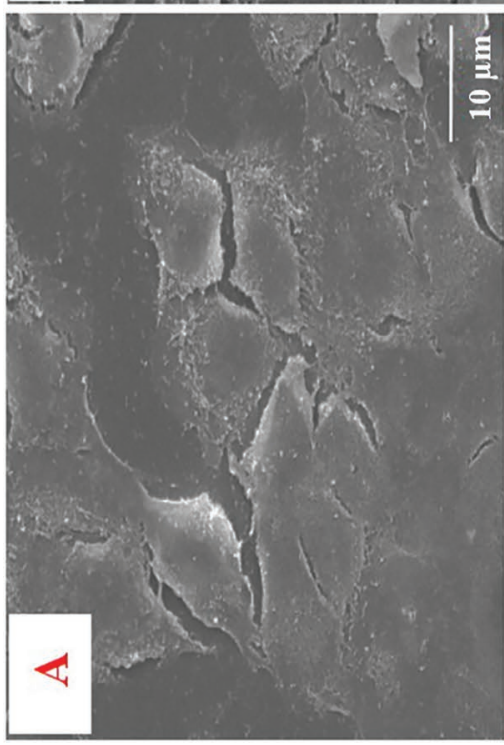

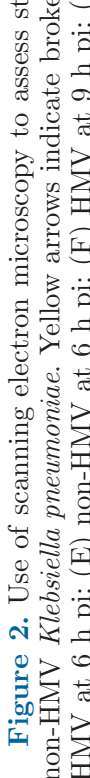



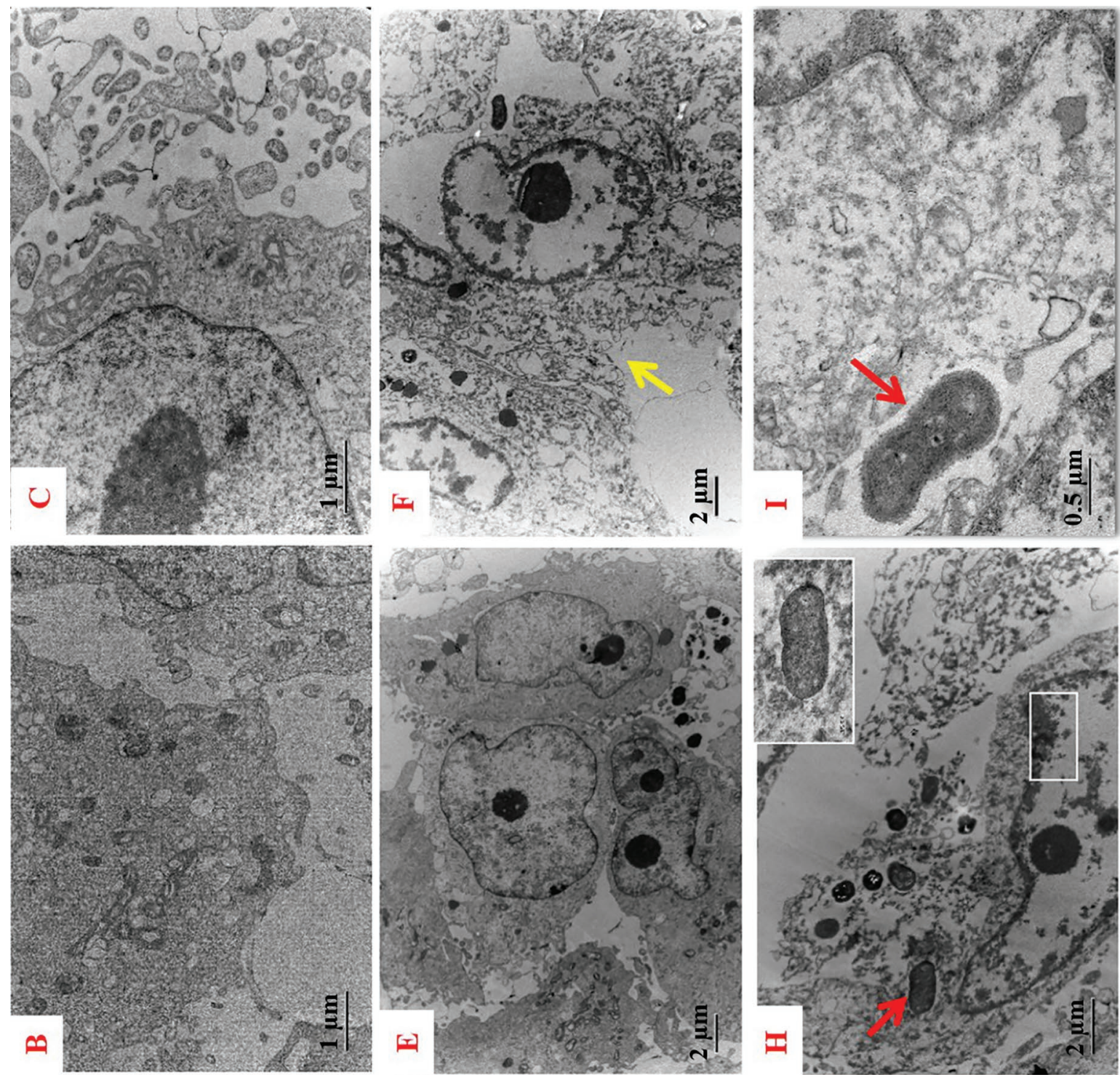

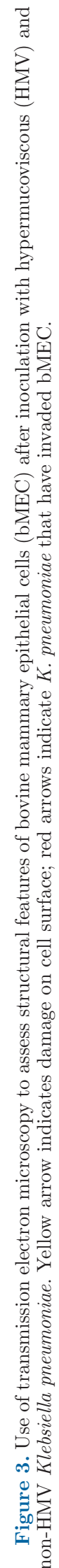
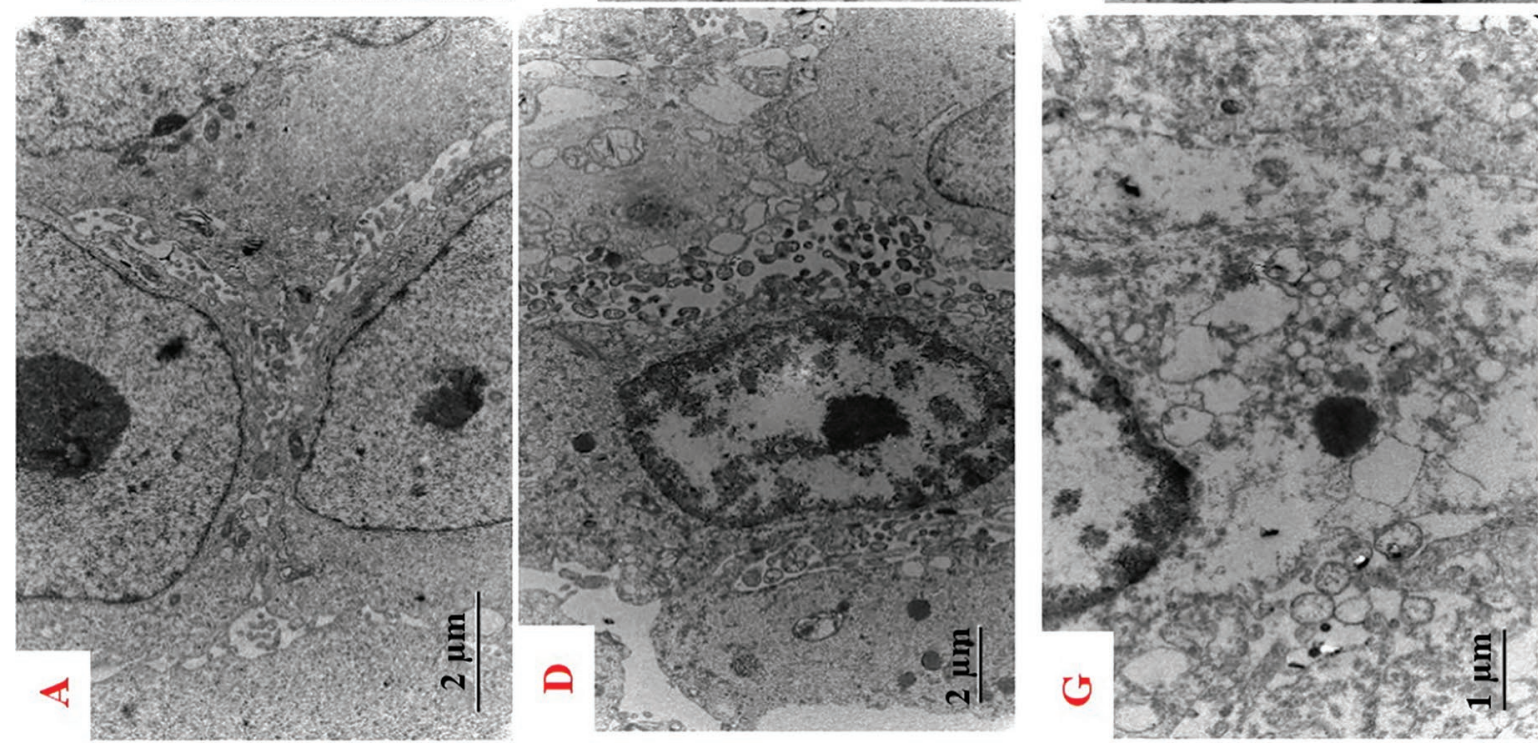

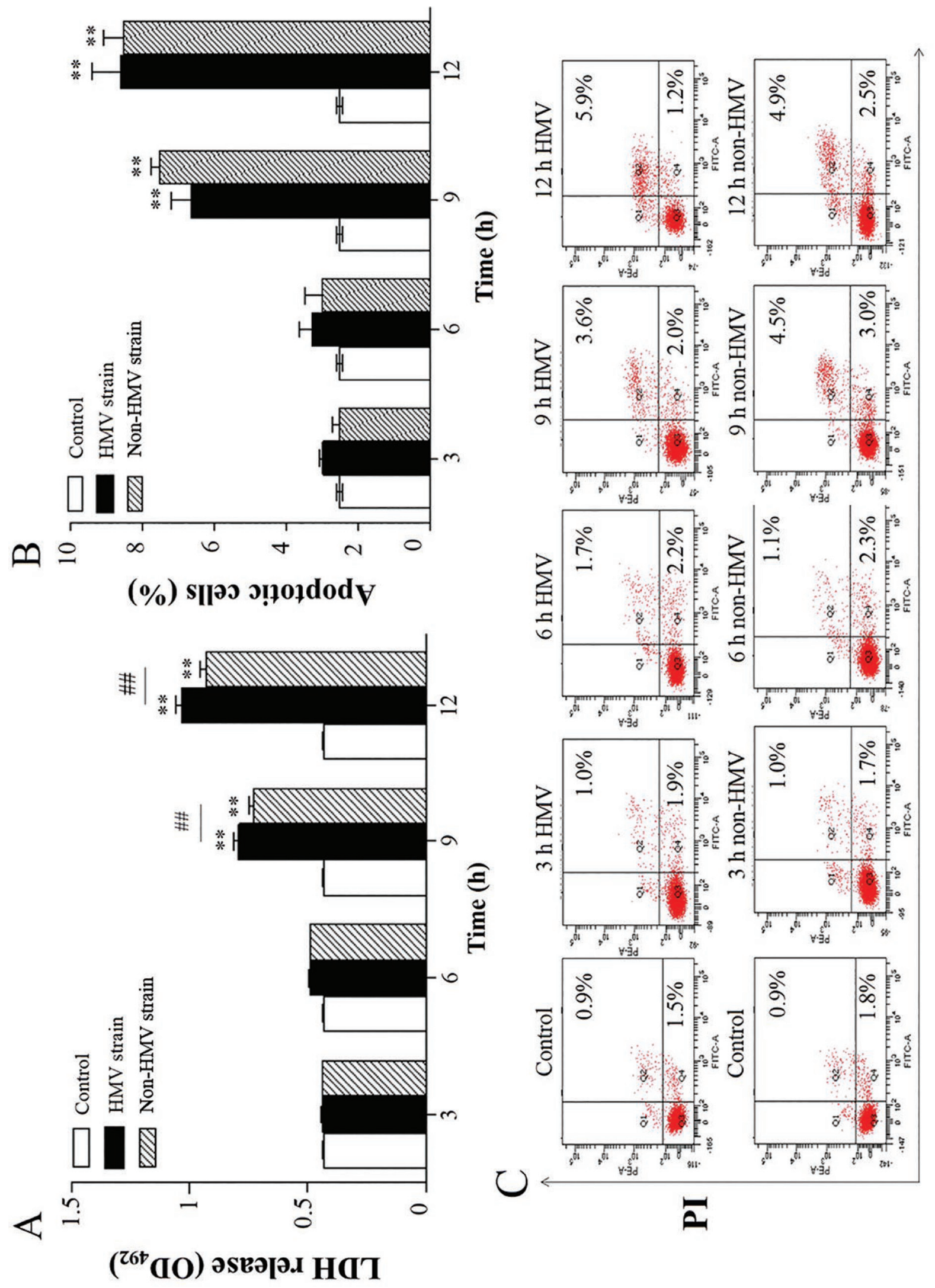

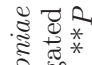

농.

竞,

$\leqslant O_{*}^{*}$

峞茞苗

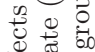

崖

死. :

讨莒.

돌 뭉

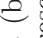

$\stackrel{2}{\exists}$

奈苦离

记

西

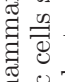

$\exists$.

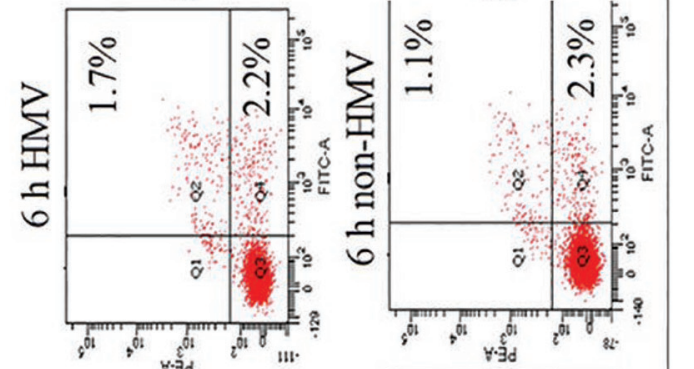

o :

.

를

芯芯空

ही

¿ㄹ

¿ढ约

ज्ञ

\& $\overline{0} 0$

过.

范范范

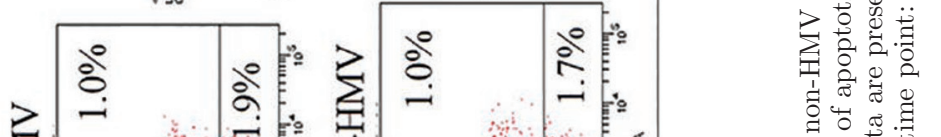

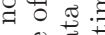

ซี

氙

$\sum 0$.

包.

ن 00.

国

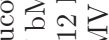

嵌

․ㅗㅇ ₹

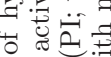

n 00

迅

○

承:

范芯范

+ن

묵

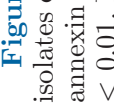


hid et al., 2017). Although virulence of K. pneumoniae isolates from cattle has been studied (Bannerman et al., 2004; Kanevsky-Mullarky et al., 2014; Osman et al., 2014), cellular pathogenicity of $K$. pneumoniae in bovine mastitis is not known. In the present study, $K$. pneumoniae isolated from $\mathrm{CM}$ adhered rapidly and invaded bMEC. Adherence of pathogens to bMEC is the initial stage of pathogenicity, whereas subsequent invasion into host cells protects bacteria from antimicrobial treatment (Chen et al., 2017). Rapid adherence of $K$. pneumoniae may facilitate intracellular invasion and contribute to development of chronic infections. In addition to high antimicrobial resistance of bovine $K$. pneumoniae in vitro (Cheng et al., 2019a), we speculated that capability to adhere and invade would increase $K$. pneumoniae resistance within the bovine udder. Compared with HMV K. pneumoniae, the non-HMV isolate had more pronounced adhesive and invasive abilities, suggesting that the latter had greater potential to damage mammary tissues. Regardless, our results did not implicate HMV phenotype as a key factor to increase the invasion ability of $K$. pneumoniae in bovine CM.

In this study, internalization of $K$. pneumoniae quickly caused obvious cellular damage (after $3 \mathrm{~h} \mathrm{pi}$ ), including membrane disruptions, fragmentation of nuclear membranes, chromatin condensation, swollen mitochondria, and even cellular collapse. Combined with subsequent cell apoptosis (6 and $9 \mathrm{~h} \mathrm{pi}$ ), we confirmed that $K$. pneumoniae was highly cytotoxic in mastitis, consistent with infections in humans (Shon et al., 2013; Cubero et al., 2016). Compared with non-HMV K. pneumoni$a e$, the HMV isolate induced more severe damage in bMEC, implying greater cytotoxicity. In the first week after Klebsiella mastitis, cows have a rapid decline in milk production that lasts for the remainder of the lactation (Gröhn et al., 2004). Based on present results,
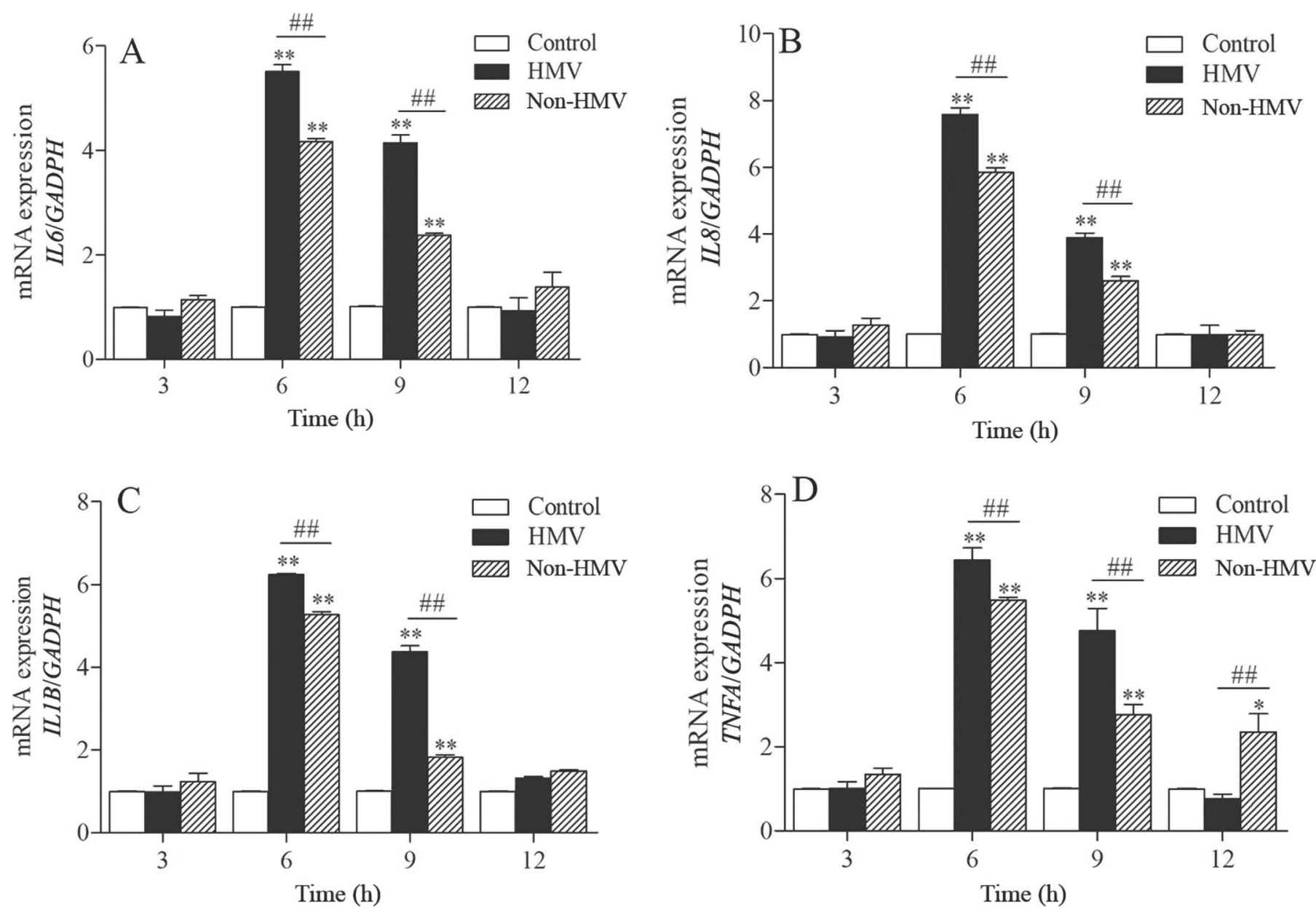

Figure 5. Relative mRNA expression of IL-6, IL-8, IL-1 $\beta$, and tumor necrosis factor- $\alpha$ (TNF- $\alpha$ ) in bovine mammary epithelial cells after inoculation with hypermucoviscous (HMV) and non-HMV Klebsiella pneumoniae. Data are presented as mean \pm SEM of 3 independent experiments. Compared with control group: ${ }^{*}=P<0.05,{ }^{* *}=P<0.01$. HMV isolate compared with strain non-HMV at the same time point: \# $=P<0.05, \# \#=P<0.01$. 
we hypothesized that cellular damage and apoptosis induced during Klebsiella CM causes substantial loss of mammary epithelial cells, substantially decreasing milk yield, even after apparent recovery from CM. Therefore, non-steroidal anti-inflammatory drugs (e.g., meloxicam) are recommended for treating CM caused by Klebsiella, to reduce inflammation and cellular damage (van Soest et al., 2018).

Previous studies have shown that bMEC could exhibit a pro-inflammatory cytokine response (TNF- $\alpha$, IL-1 $\beta$, IL-6, and IL-8) that can regulate the host cells' damage (Fitzgerald et al., 2007; Günther et al., 2010; Fujisawa et al., 2019). . In the present study, we found elevated mRNA transcriptions of TNF- $\alpha$, IL-1 $\beta$, IL-6, and IL-8 genes in cells inoculated with both $K$. pneumoniae isolates, as well as production of more TNF- $\alpha$,
IL-1 $\beta$, and IL-8 in either HMV or non-HMV isolate, which implied that these are main epithelial effectors against $K$. pneumoniae. Bovine MEC have an important role in protecting the mammary gland from severe inflammation caused by invading pathogens (Wellnitz et al., 2006). Pro-inflammatory cytokines such as TNF- $\alpha$, IL-1 $\beta$, IL-6, and IL-8 are main immunomodulators produced by bMEC during the early stage of infection and are responsible for endotoxic shock in acute mastitis (Breyne et al., 2018), which could initiate the immune response and activate leukocytes in the udder after stimulation by molecules released from microorganisms (Cheng et al., 2019b).

A previous study found increased concentrations of TNF- $\alpha$, IL-1 $\beta$, and IL-8 in mammary glands infected with K. pneumoniae (Bannerman et al., 2004), consis-
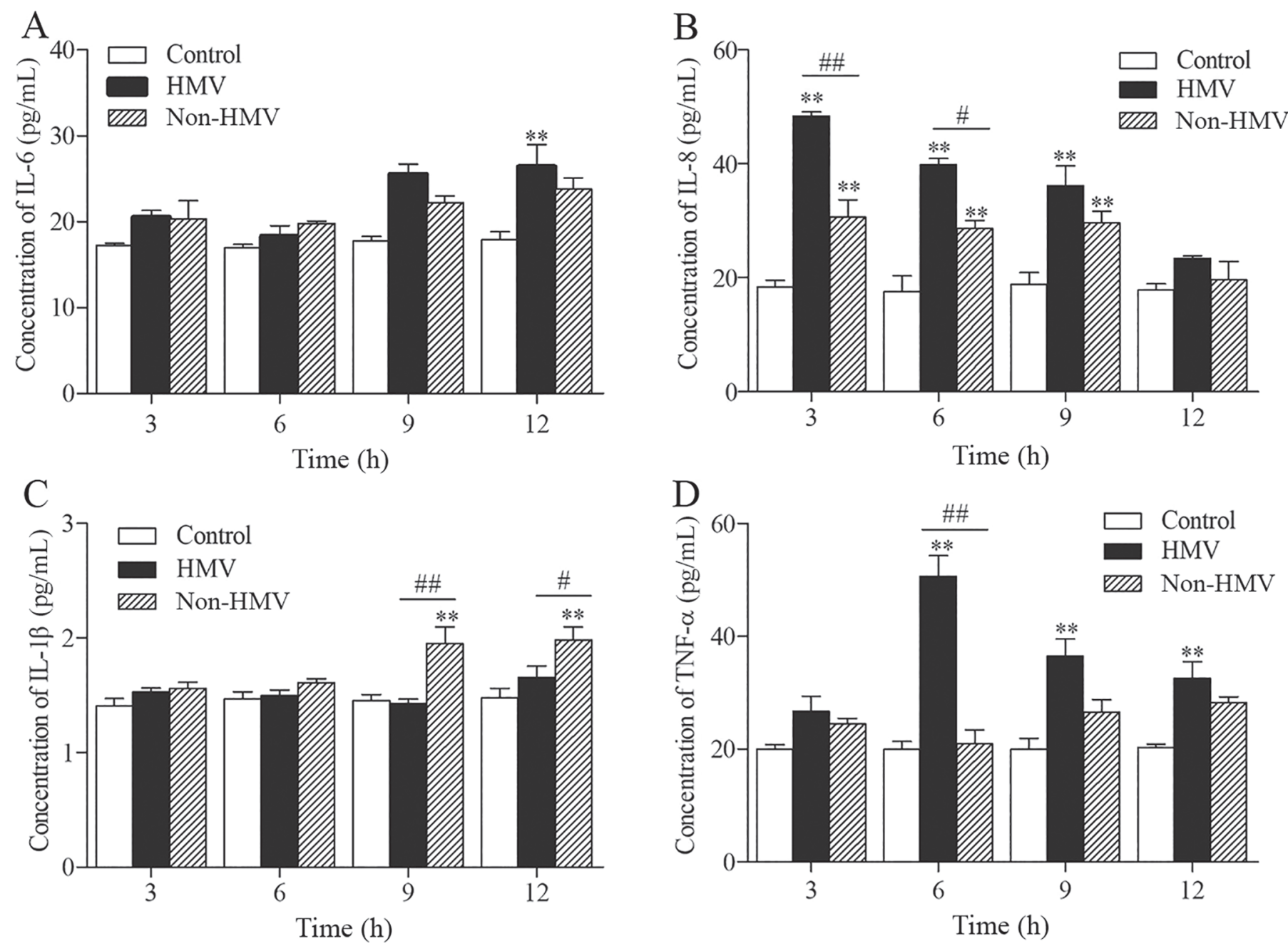

Figure 6. Protein expression of IL-6, IL-8, IL-1 $\beta$, and tumor necrosis factor- $\alpha$ (TNF- $\alpha$ ) in bovine mammary epithelial cell supernatant after inoculation with hypermucoviscous (HMV) or non-HMV Klebsiella pneumoniae isolates. Data are presented as mean \pm SEM of 3 independent experiments. Compared with control group: ${ }^{*}=P<0.05,{ }^{* *}=P<0.01$. HMV compared with non-HMV isolate at the same time point: \# $P<0.05, \# \#=P<0.01$. 
tent with our results in the bMEC infection model. Tumor necrosis factor- $\alpha$ and IL-1 $\beta$ are potent inducers of fever and acute-phase protein synthesis. In this study, TNF- $\alpha$ and IL-1 $\beta$ mRNA and protein levels increased earlier $(<9 \mathrm{~h})$ than reported in the previous study (>12 h; Bannerman et al., 2004); therefore, we inferred that bMEC may contribute to initial immune defense responses. Interleukin- 8 is a chemotactic agent that facilitates neutrophil recruitment to the site of infection to kill invading pathogens (Leitner et al., 2000). An immediate increase in IL- $8(<6 \mathrm{~h})$ released by bMEC after $K$. pneumoniae challenge implied rapid recruitment of neutrophils. Additionally, we found increased production of IL-6, IL-8, and TNF- $\alpha$ in bMEC exposed to the HMV isolate, implying a more profound proinflammatory response.

Our intention was to select 2 isolates with similar virulence profiles, as determined in our previous study (Gao et al., 2019), to characterize differences in HMV phenotype and its role in pathogenicity of bovine $K$. pneumoniae. However, the importance of the HMV phenotype was not clearly elucidated. The major limitation was that only 1 isolate for each phenotype (HMV-positive and HMV-negative) was compared. Although we used 2 isolates that were similar for several important virulence factors, other virulence factors that were not detected in the previous study (Gao et al., 2019) may have differed between the 2 isolates and perhaps contributed to differences in pathogenicity of bovine $K$. pneumoniae on bMEC. Therefore, we must emphasize that this was a preliminary exploration of the role of the HMV phenotype on pathogenicity of bovine $K$. pneumoniae. In a further study, whole-genome sequencing of $K$. pneumoniae isolates should be performed, to compare these 2 isolates for other virulence factors. In addition, as a next step, in vivo infection models (mice and cows) should be developed to better characterize virulence.

\section{CONCLUSIONS}

Klebsiella pneumoniae isolated from bovine CM adhered to and invaded bMEC, inducing damage and causing apoptosis. In addition, $K$. pneumoniae increased transcriptional expression of $I L 6, I L 8, I L 1 B$, and TNFA genes and production of TNF- $\alpha$, IL-1 $\beta$, and IL- 8 in inoculated bMEC. The HMV K. pneumoniae isolate had lower adhesive and invasive ability compared with a non-HMV isolate, but induced more serious damage to bMEC. Therefore, K. pneumoniae was cytopathogenic on bMEC and induced pro-inflammatory responses. However, the HMV phenotype did not have a key role in pathogenicity of $K$. pneumoniae on bMEC. This study preliminarily explored the pathogenic mechanism of Klebsiella mastitis at the cellular level and indicated that more attention should be paid to reduction of milk yield due to damage of bMEC.

\section{ACKNOWLEDGMENTS}

This study was financially supported by Beijing Municipal Natural Science Foundation (No. 6192013, Beijing, China), the National Key R\&D Project (No. 2016YFD0501203, Beijing, China), the National Natural Science Foundation of China (No. 31772813, 31572587, 31660730 and 31550110200, Beijing, China), and the High-end Foreign Experts Recruitment Program (No. GDT20171100013, Beijing, China). The authors have not stated any conflicts of interest.

\section{REFERENCES}

Almeida, R. A., B. Dogan, S. Klaessing, Y. H. Schukken, and S. P. Oliver. 2011. Intracellular fate of strains of Escherichia coli isolated from dairy cows with acute or chronic mastitis. Vet. Res. Commun. 35:89-101. https://doi.org/10.1007/s11259-010-9455-5.

Bannerman, D. D., M. J. Paape, W. R. Hare, and J. C. Hope. 2004. Characterization of the bovine innate immune response to intramammary infection with Klebsiella pneumoniae. J. Dairy Sci. 87:2420-2432. https://doi.org/10.3168/jds.S0022-0302(04)73365 -2 .

Barry, T., R. Powell, and F. Gannon. 1990. A general method to generate DNA probes for microorganisms. Biotechnology (NY). $8: 233-236$.

Breyne, K., J. Steenbrugge, K. Demeyere, C. G. Lee, J. A. Elias, W. Petzl, D. G. E. Smith, P. Germon, and E. Meyer. 2018. Immunomodulation of host chitinase 3-like 1 during a mammary pathogenic Escherichia coli infection. Front. Immunol. 9:1143. https:// doi.org/10.3389/fimmu.2018.01143.

Chen, W., Y. Liu, L. Zhang, X. Gu, G. Liu, M. Shahid, J. Gao, T. Ali, and B. Han. 2017. Nocardia cyriacigeorgica from bovine mastitis induced in vitro apoptosis of bovine mammary epithelial cells via activation of mitochondrial-caspase pathway. Front. Cell. Infect. Microbiol. 7:194. https://doi.org/10.3389/fcimb.2017.00194.

Cheng, J., W. Qu, H. W. Barkema, D. B. Nobrega, J. Gao, G. Liu, J. De Buck, J. P. Kastelic, H. Sun, and B. Han. 2019a. Antimicrobial resistance profiles of 5 common bovine mastitis pathogens in large Chinese dairy herds. J. Dairy Sci. 102:2416-2426. https://doi.org/ 10.3168/jds.2018-15135.

Cheng, W. N., C. H. Jeong, H. G. Seo, and S. G. Han. 2019b. Moringa extract attenuates inflammatory responses and increases gene expression of casein in bovine mammary epithelial cells. Animals (Basel) 9:E391. https://doi.org/10.3390/ani9070391.

Cubero, M., I. Grau, F. Tubau, R. Pallarés, M. A. Dominguez, J. Liñares, and C. Ardanuy. 2016. Hypervirulent Klebsiella pneumoniae clones causing bacteremia in adults in a teaching hospital in Barcelona, Spain (2007-2013). Clin. Microbiol. Infect. 22:154-160. https://doi.org/10.1016/j.cmi.2015.09.025.

Davies, Y. M., M. P. Cunha, M. G. Oliveira, M. C. Oliveira, N. Philadelpho, D. C. Romero, L. Milanelo, M. B. Guimaraes, A. J. Ferreira, A. M. Moreno, L. R. Sa, and T. Knobl. 2016. Virulence and antimicrobial resistance of Klebsiella pneumoniae isolated from passerine and psittacine birds. Avian Pathol. 45:194-201. https:// doi.org/10.1080/03079457.2016.1142066.

Fang, C. T., Y. P. Chuang, C. T. Shun, S. C. Chang, and J. T. Wang. 2004. A novel virulence gene in Klebsiella pneumoniae strains causing primary liver abscess and septic metastatic complications. J. Exp. Med. 199:697-705. https://doi.org/10.1084/jem.20030857.

Fitzgerald, D. C., K. G. Meade, A. N. McEvoy, L. Lillis, E. P. Murphy, D. E. MacHugh, and A. W. Baird. 2007. Tumour necrosis 
factor- $\alpha(\mathrm{TNF}-\alpha)$ increases nuclear factor $\kappa \mathrm{B}(\mathrm{NF}-\kappa \mathrm{B})$ activity in and interleukin-8 (IL-8) released from bovine mammary epithelial cells. Vet. Immunol. Immunopathol. 116:59-68. https://doi.org/10 .1016/j.vetimm.2006.12.008

Fujisawa, S., S. Konnai, T. Okagawa, M. Naoya, T. Akina, S. Yasuhiko, M. Shiro, and K. Ohashi. 2019. Effects of bovine tumor necrosis factor alpha decoy receptors on cell death and inflammatory cytokine kinetics: Potential for bovine inflammation therapy. BMC Vet. Res. 15:68. https://doi.org/10.1186/s12917-019-1813-0.

Gao, J., H. W. Barkema, L. Zhang, G. Liu, Z. Deng, L. Cai, R. Shan, S. Zhang, J. Zou, J. P. Kastelic, and B. Han. 2017. Incidence of clinical mastitis and distribution of pathogens on large Chinese dairy farms. J. Dairy Sci. 100:4797-4806. https://doi.org/10.3168/ jds.2016-12334.

Gao, J., S. M. Li, J. Zhang, Y. N. Zhou, S. Y. Xu, H. W. Barkema, D. B. Nobrega, C. Y. Zhu, and B. Han. 2019. Prevalence of potential virulence genes in Klebsiella spp. isolated from cows with clinical mastitis on large Chinese dairy farms. Foodborne Pathog. Dis. 16:856-863. https://doi.org/10.1089/fpd.2019.2657.

Gilbert, F. B., P. Cunha, K. Jensen, E. J. Glass, G. Foucras, C. Robert-Granie, R. Rupp, and P. Rainard. 2013. Differential response of bovine mammary epithelial cells to Staphylococcus aureus or Escherichia coli agonists of the innate immune system. Vet. Res. 44:40. https://doi.org/10.1186/1297-9716-44-40.

Gröhn, Y. T., D. J. Wilson, R. N. Gonzalez, J. A. Hertl, H. Schulte, G. Bennett, and Y. H. Schukken. 2004. Effect of pathogen-specific clinical mastitis on milk yield in dairy cows. J. Dairy Sci. 87:33583374. https://doi.org/10.3168/jds.S0022-0302(04)73472-4.

Günther, J., S. Liu, K. Esch, H. J. Schuberth, and H. M. Seyfert. 2010. Stimulated expression of TNF- $\alpha$ and IL-8, but not of lingual antimicrobial peptide reflects the concentration of pathogens contacting bovine mammary epithelial cells. Vet. Immunol. Immunopathol. 135:152-157. https://doi.org/10.1016/j.vetimm.2009 .11 .004 .

Holt, K. E., H. Wertheim, R. N. Zadoks, S. Baker, C. A. Whitehouse, D. Dance, A. Jenney, T. R. Connor, L. Y. Hsu, J. Severin, S. Brisse, H. Cao, J. Wilksch, C. Gorrie, M. B. Schultz, D. J. Edwards, K. V. Nguyen, T. V. Nguyen, T. T. Dao, M. Mensink, V. L. Minh, N. T. Nhu, C. Schultsz, K. Kuntaman, P. N. Newton, C. E. Moore, R. A. Strugnell, and N. R. Thomson. 2015. Genomic analysis of diversity, population structure, virulence, and antimicrobial resistance in Klebsiella pneumoniae, an urgent threat to public health. Proc. Natl. Acad. Sci. USA 112:E3574-E3581. https://doi .org/10.1073/pnas.1501049112.

Jang, S., L. Wheeler, R. B. Carey, B. Jensen, C. M. Crandall, K. N. Schrader, D. Jessup, K. Colegrove, and F. M. Gulland. 2010. Pleuritis and suppurative pneumonia associated with a hypermucoviscosity phenotype of Klebsiella pneumoniae in California sea lions (Zalophus californianus). Vet. Microbiol. 141:174-177. https://doi .org/10.1016/j.vetmic.2009.07.032.

Kanevsky-Mullarky, I., A. J. Nedrow, S. Garst, W. Wark, M. Dickenson, C. S. Petersson-Wolfe, and R. N. Zadoks. 2014. Short communication: Comparison of virulence factors in Klebsiella pneumoniae strains associated with multiple or single cases of mastitis. J. Dairy Sci. 97:2213-2218. https://doi.org/10.3168/jds.2013-7140.

Leitner, G., E. Shoshani, O. Krifucks, M. Chaffer, and A. Saran. 2000. Milk leucocyte population patterns in bovine udder infection of different aetiology. J. Vet. Med. B Infect. Dis. Vet. Public Health 47:581-589. https://doi.org/10.1046/j.1439-0450.2000.00388.x.

National Mastitis Council. 2017. Laboratory Handbook on Bovine Mastitis. NMC Inc., Madison, WI.

Olde Riekerink, R. G. M., H. W. Barkema, D. F. Kelton, and D. T. Scholl. 2008. Incidence rate of clinical mastitis on Canadian dairy farms. J. Dairy Sci. 91:1366-1377. https://doi.org/10.3168/ jds.2007-0757.

Oliveira, L., C. Hulland, and P. L. Ruegg. 2013. Characterization of clinical mastitis occurring in cows on 50 large dairy herds in Wis- consin. J. Dairy Sci. 96:7538-7549. https://doi.org/10.3168/jds 2012-6078.

Osman, K. M., H. M. Hassan, A. Orabi, and A. S. Abdelhafez. 2014. Phenotypic, antimicrobial susceptibility profile and virulence factors of Klebsiella pneumoniae isolated from buffalo and cow mastitic milk. Pathog. Glob. Health 108:191-199. https://doi.org/10 .1179/2047773214Y.0000000141.

Pereyra, E. A., F. Picech, M. S. Renna, C. Baravalle, C. S. Andreotti, R. Russi, L. F. Calvinho, C. Diez, and B. E. Dallard. 2016. Detection of Staphylococcus aureus adhesion and biofilm-producing genes and their expression during internalization in bovine mammary epithelial cells. Vet. Microbiol. 183:69-77. https://doi.org/10 .1016/j.vetmic.2015.12.002.

Roberson, J. R., L. D. Warnick, and G. Moore. 2004. Mild to moderate clinical mastitis: Efficacy of intramammary amoxicillin, frequent milk-out, a combined intramammary amoxicillin, and frequent milk-out treatment versus no treatment. J. Dairy Sci. 87:583-592. https://doi.org/10.3168/jds.S0022-0302(04)73200-2.

Schukken, Y., M. Chuff, P. Moroni, A. Gurjar, C. Santisteban, F. Welcome, and R. Zadoks. 2012. The "other" gram-negative bacteria in mastitis: Klebsiella, Serratia, and more. Vet. Clin. North Am. Food Anim. Pract. 28:239-256. https://doi.org/10.1016/j .cvfa.2012.04.001

Shahid, M., J. Wang, X. Gu, W. Chen, T. Ali, J. Gao, D. Han, R. Yang, S. Fanning, and B. Han. 2017. Prototheca zopfii induced ultrastructural features associated with apoptosis in bovine mammary epithelial cells. Front. Cell. Infect. Microbiol. 7:299. https:// doi.org/10.3389/fcimb.2017.00299.

Shon, A. S., R. P. Bajwa, and T. A. Russo. 2013. Hypervirulent (hypermucoviscous) Klebsiella pneumoniae: A new and dangerous breed. Virulence 4:107-118. https://doi.org/10.4161/viru.22718.

Twenhafel, N. A., C. A. Whitehouse, E. L. Stevens, H. E. Hottel, C. D Foster, S. Gamble, S. Abbott, J. M. Janda, N. Kreiselmeier, and K. E. Steele. 2008. Multisystemic abscesses in African green monkeys (Chlorocebus aethiops) with invasive Klebsiella pneumoniaeIdentification of the hypermucoviscosity phenotype. Vet. Pathol. 45:226-231. https://doi.org/10.1354/vp.45-2-226.

van Soest, F. J. S., E. Abbeloos, S. McDougall, and H. Hogeveen. 2018. Addition of meloxicam to the treatment of bovine clinical mastitis results in a net economic benefit to the dairy farmer. J. Dairy Sci. 101:3387-3397. https://doi.org/10.3168/jds.2017-12869.

Wellnitz, O., P. Reith, S. C. Haas, and H. H. D. Meyer. 2006. Immune relevant gene expression of mammary epithelial cells and their influence on leukocyte chemotaxis in response to different mastitis pathogens. Vet. Med. 51:125-132. https://doi.org/10.17221/5531 -VETMED.

Zbinden, C., P. Pilo, J. Frey, R. M. Bruckmaier, and O. Wellnitz. 2015. The immune response of bovine mammary epithelial cells to live or heat-inactivated Mycoplasma bovis. Vet. Microbiol. 179:336-340. https://doi.org/10.1016/j.vetmic.2015.07.007.

Zbinden, C., R. Stephan, S. Johler, N. Borel, J. Bünter, R. M. Bruckmaier, and O. Wellnitz. 2014. The inflammatory response of primary bovine mammary epithelial cells to Staphylococcus aureus strains is linked to the bacterial phenotype. Plos One 9:e87374. https://doi.org/10.1371/journal.pone.0087374.

\section{ORCIDS}

Jv Zhang ๑ https://orcid.org/0000-0002-1682-7614

Bo Han (i) https://orcid.org/0000-0002-4798-7725

Herman W. Barkema @ https://orcid.org/0000-0002-9678-8378

Eduardo R. Cobo @ ㄴ https://orcid.org/0000-0001-5450-7673

John P. Kastelic () https://orcid.org/0000-0003-4607-3355

Jian Gao @i https://orcid.org/0000-0001-5059-2698 